\title{
Multivalued Pseudo-Picard Operators and Fixed Point Results
}

\author{
Gülhan Minak, Özlem Acar, and Ishak Altun \\ Department of Mathematics, Faculty of Science and Arts, Kirikkale University, Yahsihan, 71450 Kirikkale, Turkey \\ Correspondence should be addressed to Ishak Altun; ishakaltun@yahoo.com
}

Received 24 May 2013; Accepted 25 July 2013

Academic Editor: Josip E. Pečarić

Copyright (C) 2013 Gülhan Minak et al. This is an open access article distributed under the Creative Commons Attribution License, which permits unrestricted use, distribution, and reproduction in any medium, provided the original work is properly cited.

We introduce the concept of multivalued pseudo-Picard (MPP) operator on a metric space. This concept is weaker than multivalued weakly Picard (MWP) operator, which is given by M. Berinde and V. Berinde (2007). Then, we give both fixed point results and examples for MPP operators. Also, we obtain some ordered fixed point results for multivalued maps as application.

\section{Introduction and Preliminaries}

Let $(X, d)$ be a metric space, and let $C B(X)$ denote the class of all nonempty, closed, and bounded subsets of $X$. It is well known that $H: C B(X) \times C B(X) \rightarrow \mathbb{R}$ defined by

$$
H(A, B)=\max \left\{\sup _{x \in A} D(x, B), \sup _{y \in B} D(y, A)\right\}
$$

is a metric on $C B(X)$, which is called Hausdorff metric, where

$$
D(x, B)=\inf \{d(x, y): y \in B\} .
$$

Let $T: X \rightarrow C B(X)$ be a map; then, $T$ is called multivalued contraction if for all $x, y \in X$ there exists $\delta \in[0,1)$ such that

$$
H(T x, T y) \leq \delta d(x, y) .
$$

In 1969, Nadler [1] proved a fundamental fixed point theorem for multivalued maps: every multivalued contraction on complete metric space has a fixed point.

Then, a lot of generalizations of the result of Nadler were given (see, e.g., [2-4]). Two important generalizations of it were given by M. Berinde and V. Berinde [5] and Mizoguchi and Takahashi [6].

In [5], M. Berinde and V. Berinde introduced the concept of multivalued weakly Picard operator as follows (for singlevalued Picard and weakly Picard operators we refer to [7-9]).

Definition 1. Let $(X, d)$ be a metric space, and let $T$ : $X \rightarrow \mathscr{P}(X)$ (the family of all nonempty subsets of $X$ ) be a multivalued operator. $T$ is said to be multivalued weakly Picard (MWP) operator if and only if for each $x \in X$ and any $y \in T x$, there exists a sequence $\left\{x_{n}\right\}$ in $X$ such that

(i) $x_{0}=x, x_{1}=y$,

(ii) $x_{n+1} \in T x_{n}$,

(iii) the sequence $\left\{x_{n}\right\}$ is convergent and its limit is a fixed point of $T$.

Then M. Berinde and V. Berinde [5] show that every Nadler [1], Reich [10], Rus [11] and Petruşel [12] type multivalued contractions on complete metric space are MWP operators. Mizoguchi and Takahashi [6], proved the following fixed point theorem. This is also an example of MWP operator.

Theorem 2. Let $(X, d)$ be a complete metric space, and let $T$ : $X \rightarrow C B(X)$ be a multivalued map. Assume that

$$
H(T x, T y) \leq k(d(x, y)) d(x, y)
$$

for all $x, y \in X$, where $k$ is an $\mathscr{M T}$-function (i.e., it satisfies

$$
\lim \sup _{s \rightarrow t^{+}} k(s)<1
$$

for all $t \in[0, \infty))$. Then $T$ is an MWP operator.

In the same paper, M. Berinde and V. Berinde [5] introduced the concepts of multivalued $(\delta, L)$-weak contraction and multivalued $(k, L)$-weak contraction and proved the following nice fixed point theorems. 
Theorem 3. Let $(X, d)$ be a complete metric space, and let $T$ : $X \rightarrow C B(X)$ be a multivalued $(\delta, L)$-weak contraction; that is, there exist two constants $\delta \in[0,1)$ and $L \geq 0$ such that

$$
H(T x, T y) \leq \delta d(x, y)+L D(y, T x)
$$

for all $x, y \in X$. Then $T$ is an MWP operator.

Theorem 4. Let $(X, d)$ be a complete metric space, and let $T$ : $X \rightarrow C B(X)$ be a multivalued ( $k, L)$-weak contraction; that is, there exist an $\mathscr{M} \mathscr{T}$-function $k$ and a constant $L \geq 0$ such that

$$
H(T x, T y) \leq k(d(x, y)) d(x, y)+L D(y, T x)
$$

for all $x, y \in X$. Then $T$ is an MWP operator.

We can find some detailed information about the singlevalued case of $(\delta, L)$-weak contraction and the nonlinear case of it in [13-15].

Recently, Samet et al. [16] introduced the notion of $\alpha$ $\psi$-contractive mappings and gave some fixed point results for such mappings. Their results are closely related to some ordered fixed point results. Then, using their idea, some authors presented fixed point results for single and multivalued mappings (see, e.g., [16-20]). First, we recall these results. Denote by $\Psi$ the family of nondecreasing functions $\psi:[0, \infty) \rightarrow[0, \infty)$ such that $\sum_{n=1}^{\infty} \psi^{n}(t)<\infty$ for all $t>0$.

Definition 5 (see [16]). Let $(X, d)$ be a metric space, $T$ be a self map on $X, \psi \in \Psi$ and $\alpha: X \times X \rightarrow[0, \infty)$ be a function. Then $T$ is called $\alpha-\psi$-contractive whenever

$$
\alpha(x, y) d(T x, T y) \leq \psi(d(x, y))
$$

for all $x, y \in X$.

Note that every Banach contraction mapping is an $\alpha-\psi$ contractive mapping with $\alpha(x, y)=1$ and $\psi(t)=\delta t$ for some $\delta \in[0,1)$.

Definition 6 (see [16]). $T$ is called $\alpha$-admissible whenever $\alpha(x, y) \geq 1$ implies that $\alpha(T x, T y) \geq 1$.

There exist some examples for $\alpha$-admissible mappings in [16]. For convenience, we mention in here one of them. Let $X=[0, \infty)$. Define $T: X \rightarrow X$ and $\alpha: X \times X \rightarrow[0, \infty)$ by $T x=\sqrt{x}$ for all $x \in X$ and $\alpha(x, y)=e^{x-y}$ for $x \geq y$ and $\alpha(x, y)=0$ for $x<y$. Then $T$ is $\alpha$-admissible.

Definition 7 (see [17]). $\alpha$ is said to have (B) property whenever $\left\{x_{n}\right\}$ is a sequence in $X$ such that $\alpha\left(x_{n}, x_{n+1}\right) \geq 1$ for all $n \in \mathbb{N}$ and $x_{n} \rightarrow x$, then $\alpha\left(x_{n}, x\right) \geq 1$ for all $n \in \mathbb{N}$.

Theorem 8 (see $[16])$. Let $(X, d)$ be a complete metric space, and let $T: X \rightarrow X$ be an $\alpha$-admissible and $\alpha-\psi$-contractive mapping. If there exists $x_{0} \in X$ such that $\alpha\left(x_{0}, T x_{0}\right) \geq 1$ and $T$ is continuous, then $T$ has a fixed point.

Remark 9. If we assume that $\alpha$ has (B) property instead of the continuity of $T$, then again $T$ has a fixed point (Theorem 2.2 of [16]). If for each $x, y \in X$ there exists $z \in X$ such that $\alpha(x, z) \geq 1$ and $\alpha(y, z) \geq 1$, then $X$ is said to have $(\mathrm{H})$ property. Therefore, if $X$ has the $(\mathrm{H})$ property in Theorems 2.1 and 2.2 in [16], then the fixed point of $T$ is unique (Theorem 2.3 of $[16])$.

Then, some generalizations of $\alpha-\psi$-contractive mappings are given as follows.

Definition 10 (see [17]). $T$ is called Ćirić type $\alpha$ - $\psi$-generalized contractive mapping whenever

$$
\alpha(x, y) d(T x, T y) \leq \psi(m(x, y))
$$

for all $x, y \in X$, where

$$
\begin{array}{r}
m(x, y)=\max \{d(x, y), d(x, T x), d(y, T y), \\
\left.\frac{1}{2}[d(x, T y)+d(y, T x)]\right\} .
\end{array}
$$

Note that every Ćirić type generalized contraction mapping is a Cirić type $\alpha-\psi$-generalized contractive mapping with $\alpha(x, y)=1$ and $\psi(t)=\lambda t$ for some $\lambda \in[0,1)$.

Theorem 11 (see [17]). Let $(X, d)$ be a complete metric space, and let $T: X \rightarrow X$ be an $\alpha$-admissible and Ćirić type $\alpha-\psi$ generalized contractive mapping. If there exists $x_{0} \in X$ such that $\alpha\left(x_{0}, T x_{0}\right) \geq 1$ and $T$ is continuous or $\alpha$ has $(B)$ property, then $T$ has a fixed point. If $X$ has the $(H)$ property, then the fixed point of $T$ is unique.

We can find some fixed point results for single-valued mappings in these directions in $[18,20]$. Now we recall some multivalued cases.

Definition 12 (see $[17,19])$. Let $(X, d)$ be a metric space, and let $T: X \rightarrow C B(X)$ be a multivalued mapping. Then $T$ is called multivalued $\alpha-\psi$-contractive whenever

$$
\alpha(x, y) H(T x, T y) \leq \psi(d(x, y))
$$

for all $x, y \in X$, and $T$ is called multivalued $\alpha_{*}-\psi$-contractive whenever

$$
\alpha_{*}(T x, T y) H(T x, T y) \leq \psi(d(x, y)),
$$

where $\alpha_{*}(T x, T y)=\inf \{\alpha(a, b): a \in T x, b \in T y\}$. Similarly if we replace $d(x, y)$ with $m(x, y)$ we can obtain Ćirić type multivalued $\alpha-\psi$-generalized contractive and Ćirić type multivalued $\alpha_{*}-\psi$-generalized contractive mappings on $X$.

Definition 13 (see $[17,19])$. Let $(X, d)$ be a metric space, and let $T: X \rightarrow C B(X)$ be a multivalued mapping.

(a) $T$ is said to be $\alpha$-admissible whenever each $x \in X$ and $y \in T x$ with $\alpha(x, y) \geq 1$ imply that $\alpha(y, z) \geq 1$ for all $z \in T y$.

(b) $T$ is said to be $\alpha_{*}$-admissible whenever each $x \in X$ and $y \in T x$ with $\alpha(x, y) \geq 1$ imply that $\alpha_{*}(T x, T y) \geq$ 1 . 
Remark 14. It is clear that $\alpha_{*}$-admissible maps are also $\alpha$ admissible, but the converse may not be true as shown in the following example.

Example 15. Let $X=[-1,1]$, and $\alpha: X \times X \rightarrow[0, \infty)$ is defined by $\alpha(x, x)=0$ and $\alpha(x, y)=1$ for $x \neq y$. Define $T$ : $X \rightarrow C B(X)$ by

$$
T x= \begin{cases}\{-x\}, & x \notin\{-1,0\} \\ \{0,1\}, & x=-1 \\ \{1\}, & x=0 .\end{cases}
$$

Leting $x=-1$ and $y=0 \in T x=\{0,1\}$, then $\alpha(x, y) \geq 1$, but $\alpha_{*}(T x, T y)=\alpha_{*}(\{0,1\},\{1\})=0$. Thus, $T$ is not $\alpha_{*}$-admissible. Now we show that, $T$ is $\alpha$-admissible with the following cases.

Case 1. If $x=0$, then $y=1$ and $\alpha(x, y) \geq 1$. Also, $\alpha(y, z) \geq 1$ since $z=-1 \in T y=\{-1\}$.

Case 2. If $x=-1$, then $y \in\{0,1\}$ and $\alpha(x, y) \geq 1$. Also, $\alpha(y, z) \geq 1$ for all $z \in T y$.

Case 3. If $x \notin\{-1,0\}$, then $y=-x$ and $\alpha(x, y) \geq 1$. Also, $\alpha(y, z) \geq 1$ since $z=x \in T y=\{x\}$.

The multivalued version of the results for $\alpha-\psi$-contractive mappings is given $[17,19]$ as follows.

Theorem 16 (see [19]). Let $(X, d)$ be a complete metric space, let $\alpha: X \times X \rightarrow[0, \infty)$ be a function, let $\psi \in \Psi$ be a strictly increasing map, and let $T: X \rightarrow C B(X), \alpha$-admissible and $\alpha-\psi$-contractive multifunction on $X$. Suppose that there exist $x_{0} \in X$ and $x_{1} \in T x_{0}$ such that $\alpha\left(x_{0}, x_{1}\right) \geq 1$. Assume that $T$ is continuous or $\alpha$ has (B) property; then $T$ has a fixed point.

Theorem 17 (see [17]). Let $(X, d)$ be a complete metric space, let $\alpha: X \times X \rightarrow[0, \infty)$ be a function, let $\psi \in \Psi$ be a strictly increasing map, and let $T: X \rightarrow C B(X), \alpha_{*}$-admissible and $\alpha_{*}-\psi$-contractive multifunction on $X$. Suppose that there exist $x_{0} \in X$ and $x_{1} \in T x_{0}$ such that $\alpha\left(x_{0}, x_{1}\right) \geq 1$. Assume that $\alpha$ has (B) property. then $T$ has a fixed point.

The purpose of this paper is to introduce the concept of multivalued pseudo-Picard (MPP) operators and present fixed point results and examples.

\section{Main Results}

Definition 18. Let $(X, d)$ be a metric space, and let $T: X \rightarrow$ $\mathscr{P}(X)$ be a multivalued operator. $T$ is said to be multivalued pseudo-Picard (MPP) operator if and only if there exist $x_{0} \in$ $X, x_{1} \in T x_{0}$ and a sequence $\left\{x_{n}\right\}$ in $X$ such that

(i) $x_{n+1} \in T x_{n}$,

(ii) the sequence $\left\{x_{n}\right\}$ is convergent and its limit is a fixed point of $T$.

Remark 19. It is clear that the operators mentioned in Theorems 16 and 17 are MPP operators. Also, note that every MWP operator is an MPP operator, but the converse may not be true as shown in the following examples.
Example 20. Let $X=[-1,1]$ and $d(x, y)=|x-y|$. Define $T: X \rightarrow C B(X)$ by

$$
T x= \begin{cases}\left\{0, x^{2}\right\}, & x \in(-1,1) \\ \{-x\}, & x \in\{-1,1\} .\end{cases}
$$

Then $T$ is not an MWP operator. Indeed, letting $x=1$, then $T x=\{-1\}$ and so $y=-1$. Therefore, $x_{n}=(-1)^{n}$ for $n \geq 0$, which is not convergent. But $T$ is MPP operator. To see this, let $x_{0}=1 / 2$ and $x_{1}=(1 / 4) \in T x_{0}=\{0,1 / 4\}$. Continuing this way, we can construct a sequence $\left\{x_{n}\right\}$ in $X$ with $x_{n+1} \in T x_{n}$ such that it is convergent to 0 , which is a fixed point of $T$.

Example 21. Let $X=[0, \infty)$ and $d(x, y)=|x-y|$. Define $T: X \rightarrow C B(X)$ by

$$
T x= \begin{cases}{\left[0, \frac{x}{2}\right],} & 0 \leq x \leq 1 \\ {[x+1, x+2],} & x>1\end{cases}
$$

Then $T$ is an MPP but not MWP operator.

Before we give our main results, we recall the following. Let $X$ and $Y$ be two topological spaces. Then a multivalued map $T: X \rightarrow \mathscr{P}(Y)$ is said to be upper semicontinuous (lower semicontinuous) if the inverse image of a closed set (open set) is closed (open). A multivalued map is continuous if it is upper as well as lower semicontinuous.

Lemma 22 (see [21]). Let $(X, d)$ be a metric space, and let $T$ : $X \rightarrow \mathscr{P}(X)$ be an upper semicontinuous map such that $T x$ is closed for all $x \in X$. If $x_{n} \rightarrow x_{0}, y_{n} \rightarrow y_{0}$ and $y_{n} \in T x_{n}$, then $y_{0} \in T x_{0}$.

Theorem 23. Let $(X, d)$ be a complete metric space and let $T$ : $X \rightarrow C B(X)$ be an $\alpha$-admissible multivalued mapping such that

$$
\begin{aligned}
\alpha(x, y) H(T x, T y) \leq & \psi(d(x, y)) \\
& +L \min \{D(x, T y), D(y, T x)\}
\end{aligned}
$$

for all $x, y \in X$, where $\psi \in \Psi$ is strictly increasing and $L \geq 0$. Suppose that there exist $x_{0} \in X$ and $x_{1} \in T x_{0}$ such that $\alpha\left(x_{0}, x_{1}\right) \geq 1$. If $T$ is upper semicontinuous or $\alpha$ has (B) property, then $T$ is an MPP operator.

Proof. Let $x_{0}$ and $x_{1}$ be as mentioned in the hypotheses. If $x_{0}=x_{1}$ or $x_{1} \in T x_{1}$, then the proof is complete. Let $x_{0} \neq x_{1}$ and $x_{1} \notin T x_{1}$, then

$$
\begin{aligned}
0 & <D\left(x_{1}, T x_{1}\right) \\
& \leq \alpha\left(x_{0}, x_{1}\right) H\left(T x_{0}, T x_{1}\right) \\
& <q \alpha\left(x_{0}, x_{1}\right) H\left(T x_{0}, T x_{1}\right)
\end{aligned}
$$


where $q>1$ is a constant. Therefore, there exists $x_{2} \in T x_{1}$ such that

$$
\begin{aligned}
0< & d\left(x_{1}, x_{2}\right) \\
< & q \alpha\left(x_{0}, x_{1}\right) H\left(T x_{0}, T x_{1}\right) \\
\leq & q \psi\left(d\left(x_{0}, x_{1}\right)\right) \\
& +q L \min \left\{D\left(x_{0}, T x_{1}\right), D\left(x_{1}, T x_{0}\right)\right\} \\
= & q \psi\left(d\left(x_{0}, x_{1}\right)\right) .
\end{aligned}
$$

Also, since $T$ is $\alpha$-admissible, $x_{1} \in T x_{0}$, and $\alpha\left(x_{0}, x_{1}\right) \geq 1$, then $\alpha\left(x_{1}, u\right) \geq 1$ for all $u \in T x_{1}$ and so $\alpha\left(x_{1}, x_{2}\right) \geq 1$. Since $\psi$ is strictly increasing, we have

$$
0<\psi\left(d\left(x_{1}, x_{2}\right)\right)<\psi\left(q \psi\left(d\left(x_{0}, x_{1}\right)\right)\right) .
$$

Get $q_{1}=\psi\left(q \psi\left(d\left(x_{0}, x_{1}\right)\right)\right) / \psi\left(d\left(x_{1}, x_{2}\right)\right)$. Then $q_{1}>1$. If $x_{2} \in$ $T x_{2}$, then the proof is complete. Let $x_{2} \notin T x_{2}$. Then

$$
\begin{aligned}
0 & <D\left(x_{2}, T x_{2}\right) \\
& \leq \alpha\left(x_{1}, x_{2}\right) H\left(T x_{1}, T x_{2}\right) \\
& <q_{1} \alpha\left(x_{1}, x_{2}\right) H\left(T x_{1}, T x_{2}\right) .
\end{aligned}
$$

Therefore, there exists $x_{3} \in T x_{2}$ such that

$$
\begin{aligned}
0< & d\left(x_{2}, x_{3}\right) \\
< & q_{1} \alpha\left(x_{1}, x_{2}\right) H\left(T x_{1}, T x_{2}\right) \\
\leq & q_{1} \psi\left(d\left(x_{1}, x_{2}\right)\right) \\
& +q_{1} L \min \left\{D\left(x_{1}, T x_{2}\right), D\left(x_{2}, T x_{1}\right)\right\} \\
= & q_{1} \psi\left(d\left(x_{1}, x_{2}\right)\right) \\
= & \psi\left(q \psi\left(d\left(x_{0}, x_{1}\right)\right)\right) .
\end{aligned}
$$

Since $T$ is $\alpha$-admissible, $x_{2} \in T x_{1}$, and $\alpha\left(x_{1}, x_{2}\right) \geq 1$, then $\alpha\left(x_{2}, u\right) \geq 1$ for all $u \in T x_{2}$. Thus, $\alpha\left(x_{2}, x_{3}\right) \geq 1$ since $x_{3} \in$ $T x_{2}$. Since $\psi$ is strictly increasing, we have

$$
0<\psi\left(d\left(x_{2}, x_{3}\right)\right)<\psi^{2}\left(q \psi\left(d\left(x_{0}, x_{1}\right)\right)\right) .
$$

Get $q_{2}=\psi^{2}\left(q \psi\left(d\left(x_{0}, x_{1}\right)\right)\right) / \psi\left(d\left(x_{1}, x_{2}\right)\right)$. Then $q_{2}>1$. If $x_{3} \in T x_{3}$, then the proof is complete. By the way, we can construct a sequence $\left\{x_{n}\right\}$ in $X$ such that $x_{n+1} \in$ $T x_{n}, x_{n} \neq x_{n+1}, \alpha\left(x_{n}, x_{n+1}\right) \geq 1$, and

$$
d\left(x_{n}, x_{n+1}\right) \leq \psi^{n}\left(q \psi\left(d\left(x_{0}, x_{1}\right)\right)\right)
$$

for all $n \in \mathbb{N}$. Now, for each $m, n \in \mathbb{N}, m>n$, we have

$$
\begin{aligned}
d\left(x_{n}, x_{m}\right) & \leq \sum_{k=n}^{m-1} d\left(x_{k}, x_{k+1}\right) \\
& \leq \sum_{k=n}^{m-1} \psi^{k}\left(q \psi\left(d\left(x_{0}, x_{1}\right)\right)\right) .
\end{aligned}
$$

Therefore, $\left\{x_{n}\right\}$ is a Cauchy sequence in $X$. Since $X$ is complete, there exists $z \in X$ such that $\lim _{n \rightarrow \infty} x_{n}=z$. If $T$ is upper semicontinuous, then from Lemma 22 , we have $z \in T z$. Now assume that $\alpha$ has (B) property. Then $\alpha\left(x_{n}, z\right) \geq$ 1 for all $n \in \mathbb{N}$. Also, since $\lim _{n \rightarrow \infty} d\left(x_{n}, z\right)=0$ and $\psi$ is continuous at 0 , then

$$
\begin{aligned}
D\left(x_{n+1}, T z\right) \leq & H\left(T x_{n}, T z\right) \\
\leq & \alpha\left(x_{n}, z\right) H\left(T x_{n}, T z\right) \\
\leq & \psi\left(d\left(x_{n}, z\right)\right) \\
& +L \min \left\{D\left(x_{n}, T z\right), D\left(z, T x_{n}\right)\right\} \\
\leq & \psi\left(d\left(x_{n}, z\right)\right) \\
& +L \min \left\{D\left(x_{n}, T z\right), d\left(z, x_{n+1}\right)\right\} \\
\longrightarrow & 0 .
\end{aligned}
$$

Therefore, we have $D(z, T z)=0$ and so $z \in T z$.

Although $\alpha_{*}$-admissibility implies $\alpha$-admissibility of $T$, we will give the following theorem because the contractive condition is slightly different from (16).

Theorem 24. Let $(X, d)$ be a complete metric space, and let $T: X \rightarrow C B(X)$ be an $\alpha_{*}$-admissible multivalued mapping such that

$$
\begin{aligned}
\alpha_{*}(T x, T y) H(T x, T y) \leq & \psi(d(x, y)) \\
& +L \min \{D(x, T y), D(y, T x)\}
\end{aligned}
$$

for all $x, y \in X$, where $\psi \in \Psi$ is strictly increasing and $L \geq 0$. Suppose that there exist $x_{0} \in X$ and $x_{1} \in T x_{0}$ such that $\alpha\left(x_{0}, x_{1}\right) \geq 1$. If $T$ is upper semicontinuous or $\alpha$ has $(B)$ property, then $T$ is an MPP operator.

Proof. Let $x_{0}$ and $x_{1}$ be as mentioned in the hypotheses, then $\alpha_{*}\left(T x_{0}, T x_{1}\right) \geq 1$ since $T$ is $\alpha_{*}$-admissible. If $x_{0}=x_{1}$ or $x_{1} \in$ $T x_{1}$, then the proof is complete. Let $x_{0} \neq x_{1}$ and $x_{1} \notin T x_{1}$, then

$$
\begin{aligned}
0 & <D\left(x_{1}, T x_{1}\right) \\
& \leq \alpha_{*}\left(T x_{0}, T x_{1}\right) H\left(T x_{0}, T x_{1}\right) \\
& <q \alpha_{*}\left(T x_{0}, T x_{1}\right) H\left(T x_{0}, T x_{1}\right),
\end{aligned}
$$

where $q>1$ is a constant. Therefore, there exists $x_{2} \in T x_{1}$ such that

$$
\begin{aligned}
0< & d\left(x_{1}, x_{2}\right) \\
< & q \alpha_{*}\left(T x_{0}, T x_{1}\right) H\left(T x_{0}, T x_{1}\right) \\
\leq & q \psi\left(d\left(x_{0}, x_{1}\right)\right) \\
& +q L \min \left\{D\left(x_{0}, T x_{1}\right), D\left(x_{1}, T x_{0}\right)\right\} \\
= & q \psi\left(d\left(x_{0}, x_{1}\right)\right) .
\end{aligned}
$$

Since $\alpha\left(x_{1}, x_{2}\right) \geq \alpha_{*}\left(T x_{0}, T x_{1}\right) \geq 1$, then $\alpha_{*}\left(T x_{1}, T x_{2}\right) \geq 1$. Since $\psi$ is strictly increasing,

$$
0<\psi\left(d\left(x_{1}, x_{2}\right)\right)<\psi\left(q \psi\left(d\left(x_{0}, x_{1}\right)\right)\right) .
$$


Get $q_{1}=\psi\left(q \psi\left(d\left(x_{0}, x_{1}\right)\right)\right) / \psi\left(d\left(x_{1}, x_{2}\right)\right)$. Then $q_{1}>1$. If $x_{2} \in$ $T x_{2}$, then the proof is complete. Let $x_{2} \notin T x_{2}$. Then

$$
\begin{aligned}
0 & <D\left(x_{2}, T x_{2}\right) \\
& \leq \alpha_{*}\left(T x_{1}, T x_{2}\right) H\left(T x_{1}, T x_{2}\right) \\
& <q_{1} \alpha_{*}\left(T x_{1}, T x_{2}\right) H\left(T x_{1}, T x_{2}\right) .
\end{aligned}
$$

Therefore, there exists $x_{3} \in T x_{2}$ such that

$$
\begin{aligned}
0< & d\left(x_{2}, x_{3}\right) \\
< & q_{1} \alpha_{*}\left(T x_{1}, T x_{2}\right) H\left(T x_{1}, T x_{2}\right) \\
\leq & q_{1} \psi\left(d\left(x_{1}, x_{2}\right)\right) \\
& +q_{1} L \min \left\{D\left(x_{1}, T x_{2}\right), D\left(x_{2}, T x_{1}\right)\right\} \\
= & q_{1} \psi\left(d\left(x_{1}, x_{2}\right)\right) \\
= & \psi\left(q \psi\left(d\left(x_{0}, x_{1}\right)\right)\right) .
\end{aligned}
$$

Since $\alpha\left(x_{2}, x_{3}\right) \geq \alpha_{*}\left(T x_{1}, T x_{2}\right) \geq 1$, then $\alpha_{*}\left(T x_{2}, T x_{3}\right) \geq 1$. By the way, we can construct a sequence $\left\{x_{n}\right\}$ in $X$ such that $x_{n+1} \in T x_{n}, x_{n} \neq x_{n+1}, \alpha\left(x_{n}, x_{n+1}\right) \geq 1$, and

$$
d\left(x_{n}, x_{n+1}\right) \leq \psi^{n}\left(q \psi\left(d\left(x_{0}, x_{1}\right)\right)\right)
$$

for all $n \in \mathbb{N}$. Now, for each $m, n \in \mathbb{N}, m>n$, we have

$$
\begin{aligned}
d\left(x_{n}, x_{m}\right) & \leq \sum_{k=n}^{m-1} d\left(x_{k}, x_{k+1}\right) \\
& \leq \sum_{k=n}^{m-1} \psi^{k}\left(q \psi\left(d\left(x_{0}, x_{1}\right)\right)\right) .
\end{aligned}
$$

Therefore, $\left\{x_{n}\right\}$ is a Cauchy sequence in $X$. Since $X$ is complete, there exists $z \in X$ such that $\lim _{n \rightarrow \infty} x_{n}=z$. If $T$ is upper semicontinuous, then from Lemma 22 , we have $z \in T z$. Now assume that $\alpha$ has (B) property. Then $\alpha\left(x_{n}, z\right) \geq$ 1 for all $n \in \mathbb{N}$. Since $T$ is $\alpha_{*}$-admissible, $\alpha_{*}\left(T x_{n}, T z\right) \geq 1$. Therefore,

$$
\begin{aligned}
D\left(x_{n+1}, T z\right) \leq & H\left(T x_{n}, T z\right) \\
\leq & \alpha_{*}\left(T x_{n}, T z\right) H\left(T x_{n}, T z\right) \\
\leq & \psi\left(d\left(x_{n}, z\right)\right) \\
& +L \min \left\{D\left(x_{n}, T z\right), D\left(z, T x_{n}\right)\right\} \\
\leq & \psi\left(d\left(x_{n}, z\right)\right) \\
& +L \min \left\{D\left(x_{n}, T z\right), d\left(z, x_{n+1}\right)\right\},
\end{aligned}
$$

and taking limit $n \rightarrow \infty$ we have $D(z, T z)=0$ and so $z \in$ $T z$.

Remark 25. If we take $\alpha: X \times X \rightarrow[0, \infty)$ by $\alpha(x, y)=$ 1 , then any multivalued mappings $T: X \rightarrow C B(X)$ are $\alpha$ admissible as well as $\alpha_{*}$-admissible. Therefore, Theorem 3 is a special case of Theorems 23 and 24 .
Remark 26. If we take $L=0$ in Theorems 23 and 24, then we have Theorems 16 and 17, respectively.

Now we give an example to illustrate our main results. Note that both Theorems 3 and 16 cannot be applied to this example.

Example 27. Let $X=[0,1] \cup\{2,3\}$ and $d(x, y)=|x-y|$. Define $T: X \rightarrow C B(X)$ by

$$
T x= \begin{cases}{\left[0, \frac{x}{2}\right],} & x \in\left[0, \frac{1}{2}\right] \\ {\left[\frac{1}{4}, \frac{3 x-1}{2}\right],} & x \in\left(\frac{1}{2}, 1\right] \\ \{x\}, & x \in\{2,3\}\end{cases}
$$

and $\alpha: X \times X \rightarrow[0, \infty)$ by

$$
\alpha(x, y)= \begin{cases}1, & x, y \in\left[0, \frac{1}{2}\right] \cup\{2,3\} \\ 0, & \text { otherwise }\end{cases}
$$

Then $T$ is an $\alpha$-admissible, and condition (16) is satisfied for $\psi(t)=t / 2$ and $L=1$. Indeed, first, we show that $T$ is an $\alpha$ admissible. Letting $x \in X$ and $y \in T x$ with $\alpha(x, y) \geq 1$, then it should be $x \in[0,1 / 2] \cup\{2,3\}$. Thus, $y \in T x \subset[0,1 / 2] \cup$ $\{2,3\}$, and hence $\alpha(y, z) \geq 1$ for all $z \in T y \subset[0,1 / 2] \cup\{2,3\}$. Therefore, $T$ is an $\alpha$-admissible.

Now we consider the following cases.

Case 1. Letting $x, y \in X$ with $\{x, y\} \cap(1 / 2,1] \neq \emptyset$, then $\alpha(x, y)=0$. Thus, (16) is satisfied. Also note that if $x=y$, then $H(T x, T y)=0$ and so (16) is satisfied. Therefore, we will consider $x \neq y$ in the following.

Case 2. Letting $x, y \in X$ with $x, y \in[0,1 / 2] \cup\{2,3\}$, then $\alpha(x, y)=1$. There are some subcases as follows.

Subcase 1. Consider that $x, y \in[0,1 / 2]$, and suppose that (without loss of generality) $x>y$; then

$$
\begin{aligned}
H(T x, T y) & =H\left(\left[0, \frac{x}{2}\right],\left[0, \frac{y}{2}\right]\right) \\
& =\frac{1}{2}(x-y) \\
& \leq \frac{1}{2} d(x, y)+\min \{D(x, T y), D(y, T x)\}
\end{aligned}
$$

and so again (16) is satisfied.

Subcase 2. Consider that $x \in[0,1 / 2]$ and $y \in\{2,3\}$; then

$$
\begin{aligned}
H(T x, T y) & =H\left(\left[0, \frac{x}{2}\right],\{y\}\right) \\
& =y-\frac{x}{2} \\
& \leq \frac{3}{2}(y-x) \\
& =\frac{1}{2}(y-x)+\min \left\{y-x, y-\frac{x}{2}\right\} \\
& =\frac{1}{2} d(x, y)+\min \{D(x, T y), D(y, T x)\} .
\end{aligned}
$$


Subcase 3. If $x=2$ and $y=3$, then

$$
\begin{aligned}
H(T x, T y) & =1 \\
& =d(x, y) \\
& \leq \frac{1}{2} d(x, y)+\min \{D(x, T y), D(y, T x)\} .
\end{aligned}
$$

Thus, (16) is satisfied.

Finally, $\alpha$ has (B) property, then by Theorem 23, $T$ is an MPP operator.

Note that since $H(T 1, T(3 / 4))=3 / 8, d(1,3 / 4)=1 / 4$, and $D(3 / 4, T 1)=0$, then condition (6) is not satisfied. Therefore, Theorem 3 cannot be applied to this example.

Also, note that, since $\alpha(2,3)=1, H(T 2, T 3)=1$, and $d(2,3)=1, T$ is not multivalued $\alpha-\psi$-contractive mapping. Therefore, Theorem 16 cannot be applied to this example.

\section{Applications}

Our results can be applied to some ordered fixed point results. First we recall some ordered notions. Let $X$ be a nonempty set and $\preceq$ be a partial order on $X$.

Definition 28 (see [22]). Let $A, B$ be two nonempty subsets of $X$; the relations between $A$ and $B$ are defined as follows.

$\left(\mathrm{r}_{1}\right)$ If for every $a \in A$, there exists $b \in B$ such that $a \preceq b$, then $A \prec{ }_{1} B$.

$\left(\mathrm{r}_{2}\right)$ If for every $b \in B$, there exists $a \in A$ such that $a \preceq b$, then $A \prec_{2} B$.

$\left(\mathrm{r}_{3}\right)$ If $A \prec_{1} B$ and $A \prec_{2} B$, then $A \prec B$.

Remark 29 (see [22]). $\prec_{1}$ and $\prec_{2}$ are different relations between $A$ and $B$. For example, let $X=\mathbb{R}, A=[1 / 2,1], B=$ $[0,1]$, and $\preceq$ be a usual order on $X$; then $A \prec_{1} B$, but $A \kappa_{2} B$; if $A=[0,1], B=[0,1 / 2]$, then $A \prec_{2} B$, while $A \kappa_{1} B$.

Remark 30 (see [22]). $\prec_{1}, \prec_{2}$, and $\prec$ are reflexive and transitive but are not antisymmetric. For instance, let $X=\mathbb{R}, A=[0,3]$, $B=[0,1] \cup 2,3]$, and $\preceq$ be a usual order on $X$; then $A \prec B$ and $B \prec A$, but $A \neq B$. Hence, they are not partial orders.

Theorem 31. Let $(X, \preceq)$ be a partially ordered set, and suppose that there exists a metric $d$ in $X$ such that $(X, d)$ is complete metric space. Let $T: X \rightarrow C B(X)$ be a multivalued mapping such that

$$
H(T x, T y) \leq \psi(d(x, y))+L \min \{D(x, T y), D(y, T x)\}
$$

for all $x, y \in X$ with $x \preceq y$, where $\psi \in \Psi$ is strictly increasing and $L \geq 0$. Suppose that there exists $x_{0} \in X$ such that $\left\{x_{0}\right\} \prec_{1} T x_{0}$. Assume that for each $x \in X$ and $y \in T x$ with $x \preceq y$, are has $y \preceq z$ for all $z \in T y$. If $T$ is upper semicontinuous or $X$ satisfies the following condition that

$\left\{x_{n}\right\} \subset X$ is a nondecreasing sequence with $x_{n} \longrightarrow x$ in $X$, then $x_{n} \preceq x \forall n$,

then $T$ has a fixed point.
Proof. Define the mapping $\alpha: X \times X \rightarrow[0, \infty)$ by

$$
\alpha(x, y)= \begin{cases}1, & x \preceq y \\ 0, & \text { otherwise }\end{cases}
$$

Then we have

$$
\begin{aligned}
\alpha(x, y) H(T x, T y) \leq & \psi(d(x, y)) \\
& +L \min \{D(x, T y), D(y, T x)\}
\end{aligned}
$$

for all $x, y \in X$. Also, since $\left\{x_{0}\right\} \prec_{1} T x_{0}$, then there exists $x_{1} \in T x_{0}$ such that $x_{0} \preceq x_{1}$ and so $\alpha\left(x_{0}, x_{1}\right) \geq 1$. Now letting $x \in X$ and $y \in T x$ with $\alpha(x, y) \geq 1$, then $x \preceq y$, and so by the hypotheses we have $y \preceq z$ for all $z \in T y$. Therefore, $\alpha(y, z) \geq 1$ for all $z \in T y$. This shows that $T$ is $\alpha$-admissible. Finally, if $T$ is upper semicontinuous or $X$ satisfies (41), then $T$ is upper semicontinuous or $\alpha$ has (B) property. Therefore, from Theorem 23, $T$ has a fixed point.

Remark 32. We can give a similar result using $\prec_{2}$ instead of $\prec_{1}$.

\section{Acknowledgment}

The authors are grateful to the referees because their suggestions contributed to the improvement of the paper.

\section{References}

[1] S. B. Nadler Jr., "Multi-valued contraction mappings," Pacific Journal of Mathematics, vol. 30, pp. 475-488, 1969.

[2] W.-S. Du, "Some new results and generalizations in metric fixed point theory," Nonlinear Analysis: Theory, Methods \& Applications, vol. 73, no. 5, pp. 1439-1446, 2010.

[3] S. Reich, "Some problems and results in fixed point theory," Contemporary Mathematics, vol. 21, pp. 179-187, 1983.

[4] T. Suzuki, "Mizoguchi-Takahashi's fixed point theorem is a real generalization of Nadler's," Journal of Mathematical Analysis and Applications, vol. 340, no. 1, pp. 752-755, 2008.

[5] M. Berinde and V. Berinde, "On a general class of multi-valued weakly Picard mappings," Journal of Mathematical Analysis and Applications, vol. 326, no. 2, pp. 772-782, 2007.

[6] N. Mizoguchi and W. Takahashi, "Fixed point theorems for multivalued mappings on complete metric spaces," Journal of Mathematical Analysis and Applications, vol. 141, no. 1, pp. 177$188,1989$.

[7] V. Berinde, "Approximating fixed points of weak $\varphi$-contractions using the Picard iteration," Fixed Point Theory, vol. 4, no. 2, pp. 131-142, 2003.

[8] V. Berinde, "General constructive fixed point theorems for Ćirić-type almost contractions in metric spaces," Carpathian Journal of Mathematics, vol. 24, no. 2, pp. 10-19, 2008.

[9] M. Păcurar, "Sequences of almost contractions and fixed points," Carpathian Journal of Mathematics, vol. 24, no. 2, pp. 101-109, 2008.

[10] S. Reich, "Fixed points of contractive functions," Bollettino dell'Unione Mathematica Italian, vol. 5, pp. 26-42, 1972.

[11] I. A. Rus, "Basic problems of the metric fixed point theory revisited. II," Studia Universitatis Babeş-Bolyai Mathematica, vol. 36, no. 1, pp. 81-99, 1991. 
[12] A. Petruşel, "On Frigon-Granas-type multifunctions," Nonlinear Analysis Forum, vol. 7, no. 1, pp. 113-121, 2002.

[13] V. Berinde, "On the approximation of fixed points of weak contractive mappings," Carpathian Journal of Mathematics, vol. 19, no. 1, pp. 7-22, 2003.

[14] V. Berinde, Iterative Approximation of Fixed Points, Springer, Berlin, Germany, 2007.

[15] M. Păcurar, "Remark regarding two classes of almost contractions with unique fixed point," Creative Mathematics and Informatics, vol. 19, no. 2, pp. 178-183, 2010.

[16] B. Samet, C. Vetro, and P. Vetro, "Fixed point theorems for $\alpha$ - $\psi$-contractive type mappings," Nonlinear Analysis: Theory, Methods \& Applications, vol. 75, no. 4, pp. 2154-2165, 2012.

[17] J. H. Asl, S. Rezapour, and N. Shahzad, "On fixed points of $\alpha-\psi$-contractive multifunctions," Fixed Point Theory and Applications, vol. 212, 6 pages, 2012.

[18] E. Karapınar and B. Samet, "Generalized $\alpha-\psi$ contractive type mappings and related fixed point theorems with applications," Abstract and Applied Analysis, vol. 2012, Article ID 793486, 17 pages, 2012.

[19] B. Mohammadi, S. Rezapour, and N. Shahzad, "Some results on fixed points of $\alpha-\psi$-Ćirić generalized multifunctions," Fixed Point Theory and Applications, vol. 24, 10 pages, 2013.

[20] H. Nawab, E. Karapınar, P. Salimi, and F. Akbar, " $\alpha$-admissible mappings and related fixed point theorems," Journal of Inequalities and Applications, vol. 114, 11 pages, 2013.

[21] V. I. Istrăţescu, Fixed Point Theory: An Introduction, D. Reidel, Dordrecht, The Netherlands, 1981.

[22] Y. Feng and S. Liu, "Fixed point theorems for multi-valued increasing operators in partial ordered spaces," Soochow Journal of Mathematics, vol. 30, no. 4, pp. 461-469, 2004. 


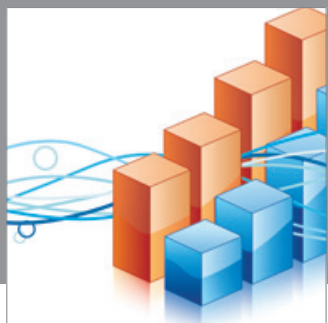

Advances in

Operations Research

mansans

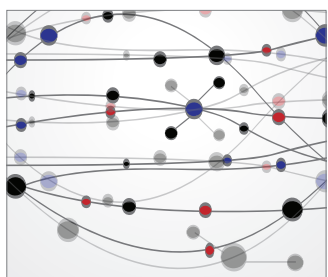

The Scientific World Journal
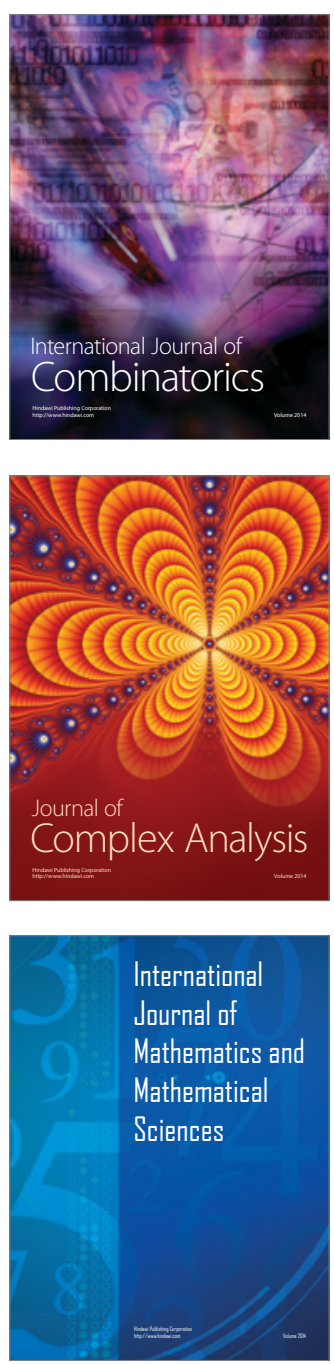
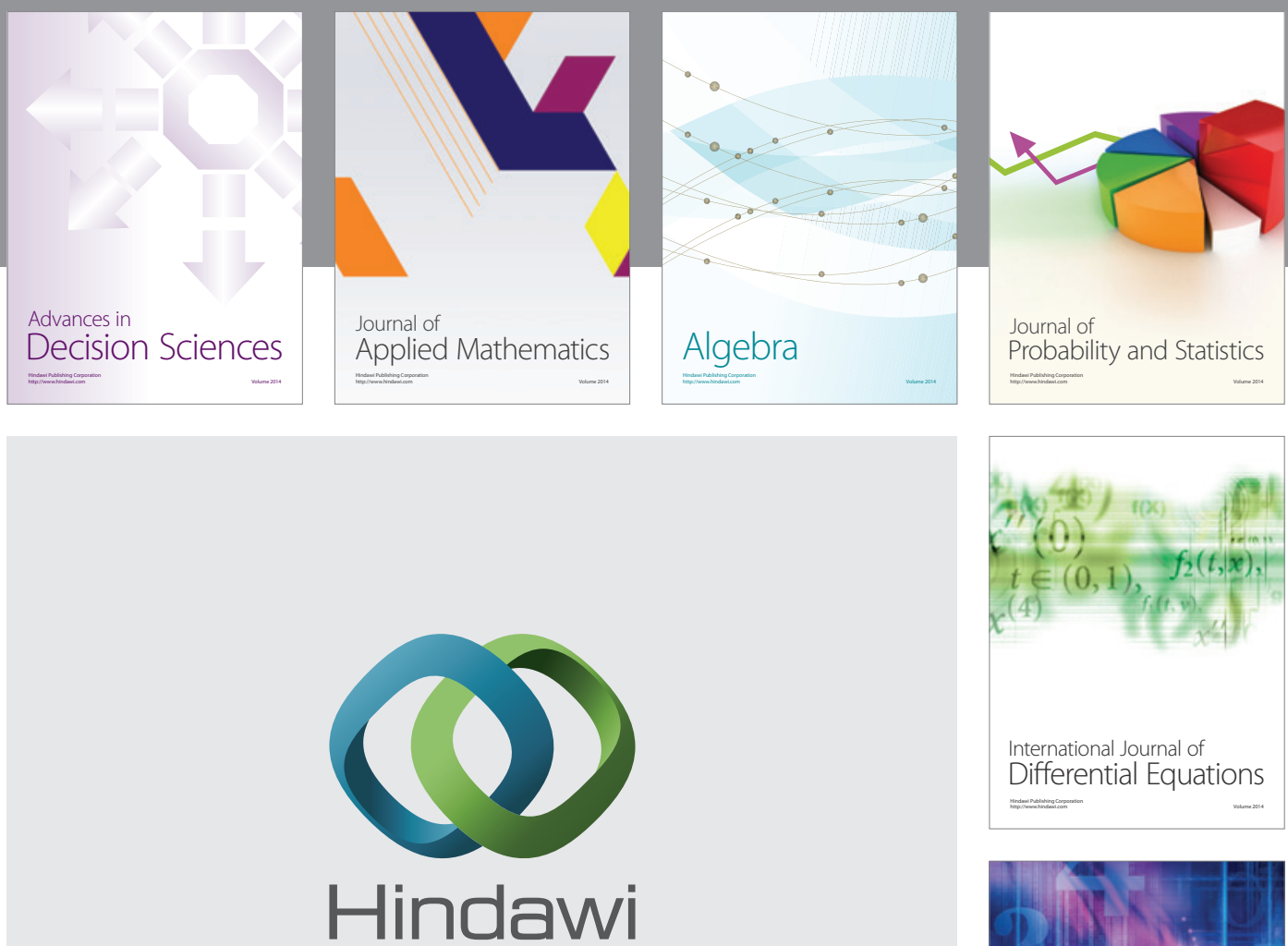

Submit your manuscripts at http://www.hindawi.com
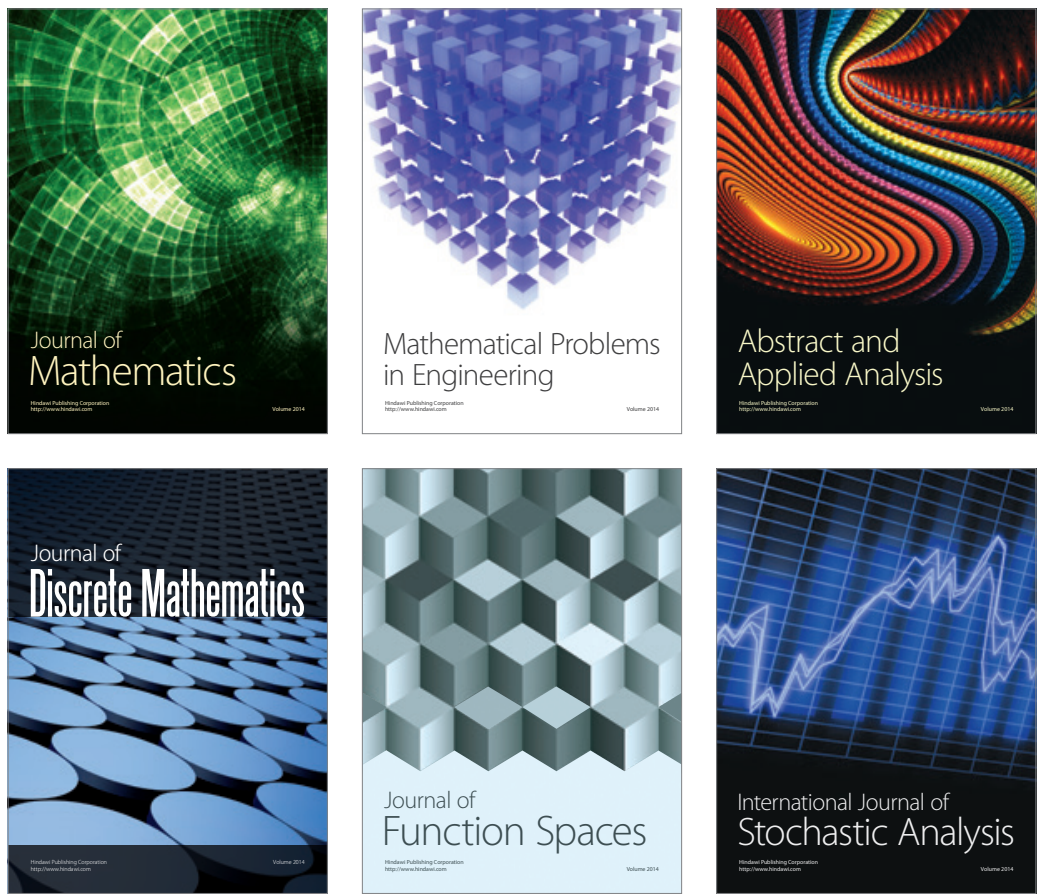

Journal of

Function Spaces

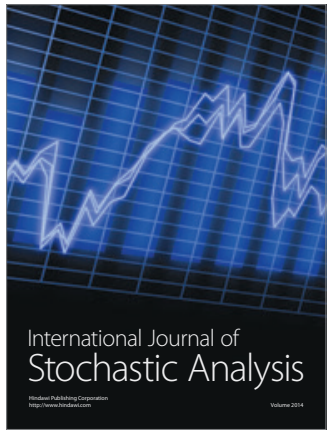

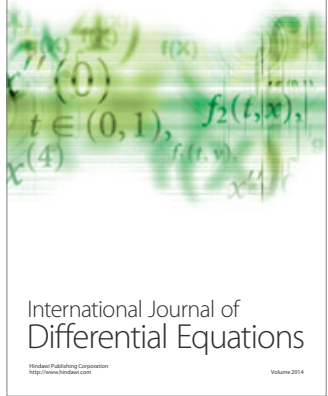
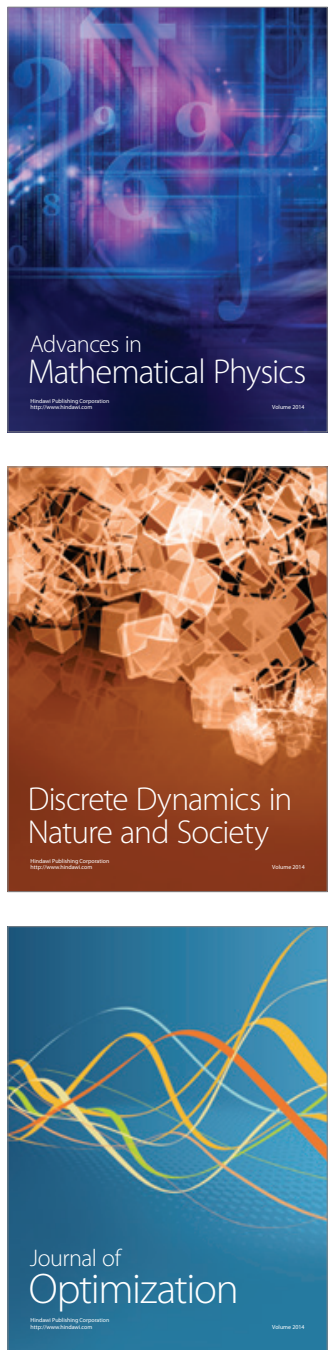